\title{
Studi Kelayakan Pabrik Gula Rafinasi dengan Kapasitas 100000 ton/tahun melalui Analisa Ekonomi
}

\author{
Aista Pudji Witari ${ }^{1}$, Gistanya Lindar Anggraini ${ }^{2}$,Erlinda Ningsih ${ }^{3}$ \\ 1,2,3 Jurusan Teknik Kimia, Institut Teknologi Adhi Tama Surabaya, Jl. Arif Rahman Hakim No. 100 \\ Surabaya, Indonesia
}

\begin{tabular}{ll}
\hline INFORMASI ARTIKEL & ABSTRACT \\
\cline { 2 - 3 } Tanggal penyerahan: & $\begin{array}{l}\text { Refined sugar is sugar that is produced from raw sugar through a refined process } \\
\text { to remove impurities and molasses attached to Raw sugar. The process that will be } \\
\text { Taned in the manufacture of refined sugar from raw sugar with carbonation } \\
\text { purification is divided into seven stages, namely: affination process, clarification } \\
\text { 31 Maret 2021 }\end{array}$ \\
process, filtration process, decolorization process, evaporation process, \\
Tanggal terbit:
\end{tabular}

Keywords: refined sugar, economic analysis, feasibility, factory

EMAIL

${ }^{1}$ Erlindaningsih84@itats.ac.id

${ }^{2}$ Kudyani@itats.ac.id

\begin{abstract}
ABSTRAK
Gula rafinasi merupakan gula yang diproduksi dari bahan baku gula mentah / raw sugar melalui proses rafinasi untuk menghilangkan kotoran serta mollases yang menempel pada Raw sugar. Proses yang akan digunakan dalam pembuatan gula rafinasi dari raw sugar dengan pemurnian karbonatasi dibagi menjadi tujuh tahapan yaitu: proses afinasi, proses klarifikasi, proses filtrasi, proses dekolorisasi, proses evaporasi, proses kristalisasi, proses pengeringan. Pabrik direncanakan beroperasi 300 hari per tahun dengan kapasitas 100.000 ton per tahun. Pabrik direncanakan akan didirikan di daerah Kabupaten Sambas, Kalimantan Barat. Dari hasil analisa ekonomi didapatkan: Internal Rate Of Return (IRR) sebesar 66\%, Pay Out Time (POT) sebesar 3,3 tahun, Break Even Point (BEP) sebesar 36\%. Berdasarkan analisa teknis dan ekonomi yang telah dilakukan, maka pabrik gula rafinasi dari raw sugar ini layak didirikan.
\end{abstract}

Kata kunci: gula rafinasi, analisis ekonomi, , kelayakan, pabrik

\section{PENDAHULUAN}

Gula rafinasi atau refined sugar merupakan gula mentah yang sudah mengalami proses pemurnian sehingga berkualitas tinggi karena kadar abu dan kadar belerang $\left(\mathrm{SO}_{2}\right)$ yang mendekati nol $^{1}$. Gula rafinasi banyak digunakan dalam industri pangan dan farmasi. Dari tahun ke tahun pertumbuhan industri pangan maupun farmasi di Indonesia semakin mengalami peningkatan. Peranan gula rafinasi bagi industri ini adalah sebagai salah satu bahan baku produksi. Secara tidak langsung dapat dikatakan bahwa kelancaran produksi industri pangan dan farmasi sangat bergantung pada ketersediaan gula rafinasi. Dengan bertambahnya jumlah industri pangan dan farmasi di Indonesia, berdampak pada meningkatnya kebutuhan gula rafinasi nasional. Pada 
awalnya gula rafinasi belum dapat diproduksi di dalam negeri sehingga kebutuhan industri dipenuhi melalui melalui impor. Sampai tahun 1996 seluruh kebutuhan industri dalam negeri masih dipenuhi melalui impor gula rafinasi ${ }^{2,3}$. Sampai saat ini pemenuhan kebutuhan akan gula rafinasi nasional tidak hanya dipenuhi dari pasokan gula rafinasi dalam negeri tetapi juga masih mengimpor dari negara penghasil.

Pengamat pertanian Khudori menjelaskan, dari sejarahnya, gula kristal rafinasi (GKR) diadakan untuk memenuhi kebutuhan pemanis industri yang tidak bisa dipenuhi pabrik gula (PG) yang ada. Ada dua cara yang bisa dilakukan untuk memenuhi kebutuhan GKR, yaitu impor sepenuhnya GKR atau mendirikan PG rafinasi dengan bahan baku gula mentah impor. Pemerintah menempuh cara kedua ${ }^{4}$.

Permintaan gula semakin meningkat, sehingga dapat memicu adanya impor gula. Beberapa faktor yang mempengaruhi impor gula adalah persediaan gula dalam negeri, produksi gula, kebutuhan gula yang meningkat dibandingkan tahun sebelumnya,harga lokal, dan kurs dolar. Jika konsumsi gula meningkat, sedangkan produksi gula yang tidak mampu memenuhi permintaan pasar, sehingga salah satu cara untuk mengatasi adalah dengan impor ${ }^{5}$. Volume impor yang meningkat sangat tidak baik untuk konsumen dan para pengusaha kecil yang menggunakan gula. Peningkatan kapasitas produksi dan persediaan gula dapat mengurangi valume impor gula, sehingga perlu dilakukan perancangan atau penambahan kapasitas produksi gula dalam negeri ${ }^{2,4}$.

Perancangan ini bertujuan untuk menentukan apakah pabrik gula rafinasi ini layak didirikan atau tidak melalui analisis ekonominya. Analisis ekonomi dimulai dari perhitungan harga alat, bahan, dan produk yang sangat dipengaruhi oleh penanaman modal dan fluktuasi ekonomi global. Perbandingan modal 40:60 bersumber dari modal sendiri dan hutang bank untuk memenuhi kebutuhan pendirian pabrik gula rafinasi berkapasitas 100000 ton/tahun. Indikator kelayakan analisis ekonomi dilihat pada hasil perhitungan nilai waktu pengembalian modal (pay out time), interest rate return (IRR), dan titik impas (break event point).

\section{METODE}

Pada proses pembuatan gula rafinasi pada intinya adalah merubah gula mentah (raw sugar) menjadi gula rafinasi (refined sugar) yang dapat memenuhi syarat untuk digunakan sebagai bahan baku industri. Proses ini memiliki beberapa tahapan, yaitu 1. Proses Afinasi 2. Proses Klarifikasi 3. Proses Filtrasi ${ }^{6}$ 4. Proses Dekolorisasi 5. Proses Evaporasi ${ }^{7}$ 6. Proses Kristalisasi ${ }^{8}$ 7. Proses Pengeringan Pada perancangan pabrik kali ini dilakukan seleksi pada proses dekolorisasi karena proses ini sangat penting untuk hasil akhir gula rafinasi yang akan diperoleh ${ }^{9,10}$. Desain flowsheet alur proses produksi disajikan pada Gambar.1.

Salah satu indikator kelayakan pabrik untuk didirikan adalah melihat hasil perhitungan analisis ekonomi. Perhitungan analisis ekonomi dilakukan dimulai sejak 2 tahun sebelum beroperasi artinya dimulai pendirian hingga 10 tahun proses produksi. Proses produksi dimulai pada tahun pertama dengan kapasitas 60\%, tahun kedua 80\%, dan tahun ketiga sampai tahun kesepuluh $100 \%$ produk. Distribusi keuangan selama 10 tahun dihitung dalam table cash flow, di mana sudah memperhatikan penyusutan alat, pajak, dan bunga yang harus dibayar. Untuk melihat untung rugi dalam mendirikan pabrik rafinasi dilakukan peninjauan terhadap nilai waktu pengembalian modal (pay out time), interest rate of return (IRR), dan titik impas (break event point $)^{11}$. Persamaan yang digunakan adalah

$$
\begin{aligned}
& \mathrm{BEP}=\frac{\mathrm{FC}+0,3 \mathrm{SVC}}{\mathrm{S}-0,75 \mathrm{VC}-\mathrm{VC}} \times \quad 100 \% \\
& \sum \frac{C F}{(1+i)^{n}} \quad=\quad \text { total modal pada akhir masa konstruksi } \\
& \underset{n}{\text { Di mana : }} \quad=\text { tahun } \\
& \mathrm{CF} \quad=\text { cash flow pada tahun ke }-\mathrm{n} \\
& \frac{1}{(1+i)^{n}} \quad=\quad \text { discount factor }(\mathrm{DF})
\end{aligned}
$$




$\begin{array}{lll}\mathrm{FC} & = & \text { Biaya tetap } \\ \mathrm{VC} & = & \text { Biaya variabel } \\ \mathrm{SVC} & & \text { Biaya semi variabel } \\ \mathrm{BEP} & & \text { Break even point }\end{array}$

Sedangkan untuk menghitung waktu pengembalian modal dapat menggunakan table Cummulative Cash Flow. Pada Tabel Cummulative Cash Flow dengan rentang tahun pertama hingga sepuluh, dilihat pada tahun ke- berapa nilai total investasi terpenuhi ${ }^{12}$.

\section{HASIL DAN PEMBAHASAN}

Pabrik Gula yang direncanakan akan didirikan di Daerah Kabupaten Sambas, Kalimantan Barat dengan jumlah total karyawan sebanyak 207 orang. Posisi jabatan untuk karyawan dibagi berdasarkan jenjang Pendidikan, karyawan proses dibagi dalam 4 shift dengan untuk 1 shift ada 8 orang, dan untuk upah selain berdasarkan Upah Minimum Regional (UMR) juga berdasarkan tingkat jabatan. Pemilihan lokasi di Kabupaten Sambas ini diharapkan dapat memenuhi kebutuhan penduduk pulau Kalimantan yang sering mengalami devisit gula. Adanya pendirian pabrik gula rafinasi di Pulau Kalimantan akan mempermudah distribusi sampai ke konsumen, sehingga harga produk menjadi lebih murah. Kebutuhan gula mengalami peningkatan khusunya gula putih hal ini ditunjukkan dengan data pada tahun 2009 terjadi peningkatan produksi gula sebesar 320.093 ton. Berdasarkan data tersebut peluang pendirian pabrik gula rafinasi sangat membantu pasokan gula.

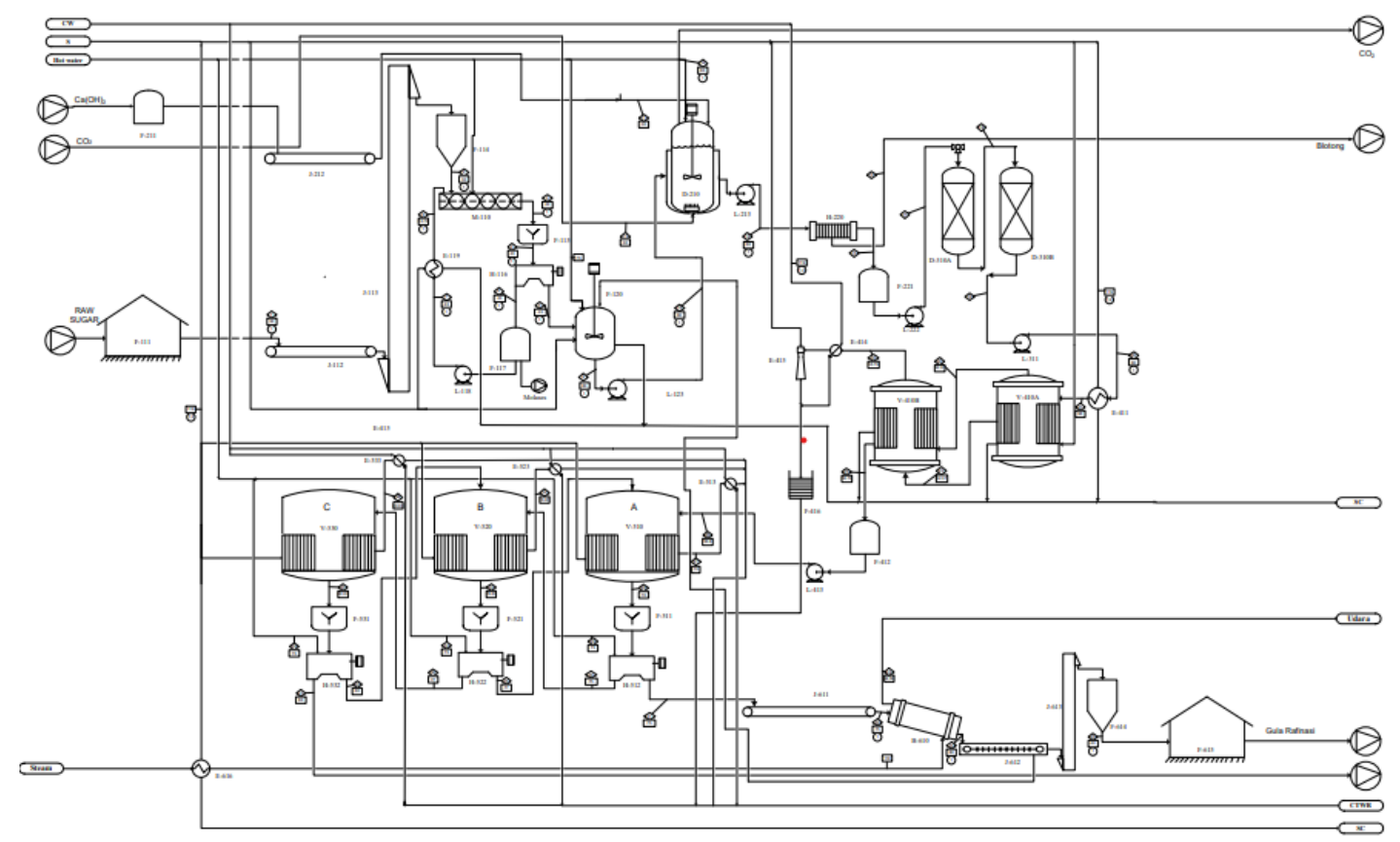

Gambar 1. Bagan Proses Pembentukan Gula Rafinasi

Pabrik gula rafinasi dengan luas tanah dan bangunan yang akan didirikan seluas $25.000 \mathrm{~m}^{2}$ dengan kapasitas sebesar 100.000 ton/tahun. Pembelian peralatan untuk pabrik ini membutuhkan dana sebesar Rp. 64,823,851,641, harga ini sudah termasuk peralatan yang dibutuhkan pada unit utilitas. Pemodalan pendirian pabrik gula rafinasi ini menggunakan strategi $40 \%$ modal bersumber dari modal sendiri dan $60 \%$ merupakan modal pinjaman kepada pihak bank. Kebutuhan biaya produksi untuk kapasitas 100\% mencapai Rp. 1,233,208,461,006.

Pada kapasitas $100 \%$ diperoleh total penjualan produk sebesar $\operatorname{Rp~1,365,989,130,000.~}$ Setelah didapatkan total biaya produksi dan total penjualan produk, maka selanjutnya dilakukan analisis ekonomi dengan tiga parameter yaitu nilai waktu pengembalian modal (pay out time), 
interest rate of return (IRR), dan titik impas (break event point). Harga produk gula rafinasi

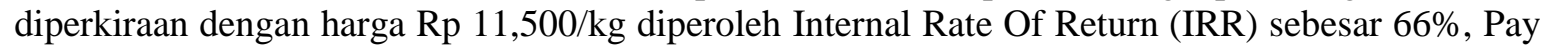
Out Time (POT) sebesar 3,3 tahun, Break Even Point (BEP) sebesar 36\%. Nilai IRR sebesar 66\% lebih tinggi dibandingkan laju tingkat bunga bank sebesar 12\%, hal ini menunjukkan bahwa laju pengembalian modal lebih tinggi dibandingkan besarnya laju bunga bank. Waktu pengembalian di bawah 5 tahun, artinya sangat menguntungkan dan dapat menjadi tingkat kepercayaan investor untuk menanamkan modal pada pabrik ini. Sedangkan untuk nilai BEP sebesar 36\% artinya pada kapasitas produksi 36,000 ton modal investasi sudah kembali.

Tabel 1. Cummulative Cash Flow

\begin{tabular}{|c|c|lc|}
\hline $\begin{array}{c}\text { Tahun } \\
\text { ke - n }\end{array}$ & Net Cash Flow & \multicolumn{2}{|c|}{ Cummulative Cash Flow } \\
\hline \hline 1 & 39.430 .079 .553 & Rp. & 39.430 .079 .553 \\
\hline 2 & 60.447 .068 .180 & Rp. & 99.877 .147 .733 \\
\hline 3 & 81.464 .056 .807 & Rp. & 181.341 .204 .539 \\
\hline 4 & 82.572 .090 .654 & Rp. & 263.913 .295 .193 \\
\hline 5 & 83.680 .124 .501 & Rp. & 347.593 .419 .694 \\
\hline 6 & 84.788 .158 .348 & Rp. & 432.381 .578 .043 \\
\hline 7 & 85.896 .192 .196 & Rp. & 518.277 .770 .238 \\
\hline 8 & 87.004 .226 .043 & Rp. & 605.281 .996 .281 \\
\hline 9 & 88.112 .259 .890 & Rp. & 693.394 .256 .171 \\
\hline 10 & 89.220 .293 .737 & Rp. & 782.614 .549 .908 \\
\hline
\end{tabular}

Tabel 2. Data Biaya Fixed Cost, Variable Cost, Semi Variable Cost, dan Sell

\begin{tabular}{|c|c|c|c|}
\hline No. & KETERANGAN & \multicolumn{2}{|l|}{ JUMLAH } \\
\hline \multirow{5}{*}{$\begin{array}{l}1 . \\
2 .\end{array}$} & \multirow{2}{*}{ 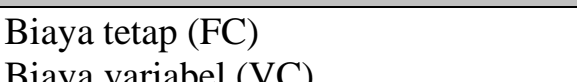 } & \multicolumn{2}{|l|}{22.424 .494 .528} \\
\hline & & & \\
\hline & \multirow{3}{*}{$\begin{array}{ll}\text { - } & \text { Bahan baku } \\
\text { - Utilitas }\end{array}$} & 916.410 .300 .000 & \\
\hline & & 123.326.276.480 & + \\
\hline & & 1.039 .736 .576 .480 & \\
\hline \multirow[t]{10}{*}{3.} & \multirow{10}{*}{$\begin{aligned} \text { Biaya } & \text { semi variabel (SVC) } \\
\text { - } & \text { Tenaga kerja } \\
\text { - } & \text { Pemeliharaan dan perbaikan } \\
\text { - } & \text { Operating supplies } \\
\text { - } & \text { Laboratorium } \\
\text { - } & \text { Paten dan royalti } \\
\text { - } & \text { Plant overhead cost } \\
\text { - } & \text { Pengeluaran umum }\end{aligned}$} & & \\
\hline & & 14.423 .500 .000 & \\
\hline & & 17.797.217.879 & \\
\hline & & 1.779 .721 .788 & \\
\hline & & 1.442 .350 .000 & \\
\hline & & 12.332 .627 .648 & \\
\hline & & 49.330 .510 .592 & \\
\hline & & 73.995.765.888 & + \\
\hline & & 171.101 .693 .795 & \\
\hline & & 171.101.693.795 & \\
\hline 4. & Total penjualan (S) & 1.365 .989 .130 .000 & \\
\hline
\end{tabular}

Sumber : Dokumentasi pribadi

$\begin{array}{rlrl}\mathrm{BEP} & = & \mathrm{FC}+0,3 \mathrm{SVC} & \\ & =\frac{73755002666,247}{206481367862,919} \times & 100 \% \\ & =\quad 36 \% & \\ & & \end{array}$




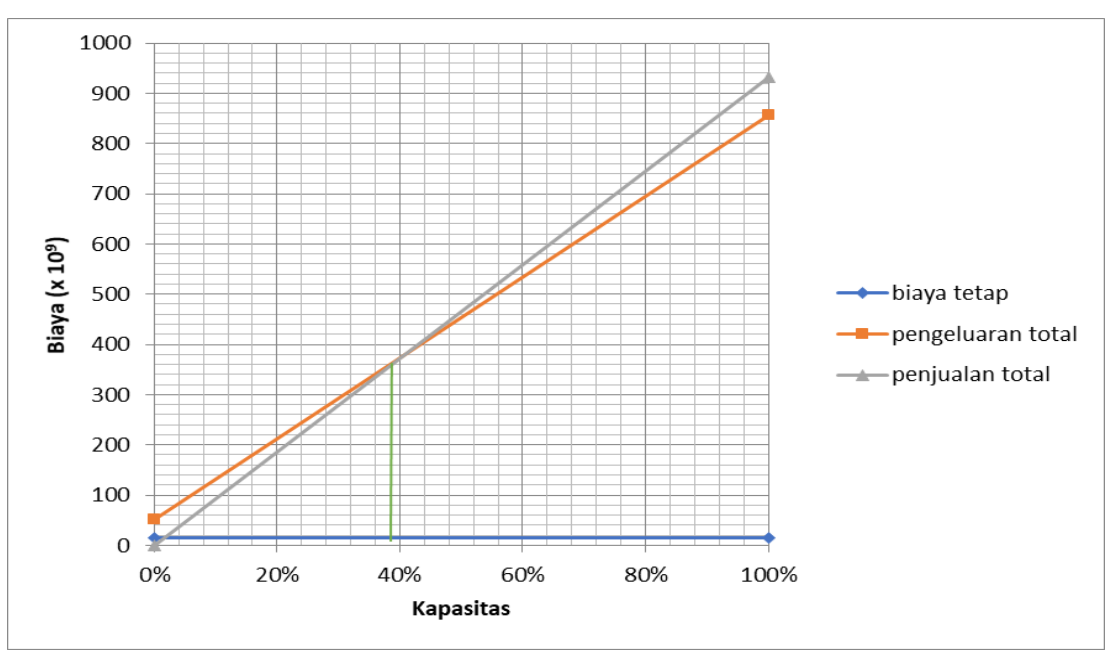

Gambar 2. Grafik Break Event Point Pabrik Gula Rafinasi

\section{UCAPAN TERIMA KASIH}

Penulis mengucapkan terima kasih kepada YPTS dan Jurusan Teknik Kimia ITATS sehingga penelitian ini dapat berlangsung.

\section{KESIMPULAN}

Kesimpulan yang didapatkan adalah :

1. Hasil perhitungan analisa ekonomi yang dilakukan untuk jangka waktu 10 tahun diperoleh nilai Internal Rate Of Return (IRR) sebesar 66\%, Pay Out Time (POT) sebesar 3,3 tahun, Break Even Point (BEP) sebesar 36\%.

2. Nilai parameter yang didapatkan menunjukkan bahwa pabrik gula rafinasi dengan bahan baku raw sugar ini dinyatakan layak didirikan.

\section{DAFTAR PUSTAKA}

[1] Fajrin, A. El, Hartono, S. \& Waluyati, L. R. Permintaan Gula Rafinasi Pada Industri Makanan Minuman Dan Farmasi Di Indonesia. Agro Ekon. 26, 150 (2016).

[2] Hairani, R. I., Aji, J. M. M. \& Januar, J. Analisis Trend Produksi dan Impor Gula Serta Faktor-Faktor yang Mempengaruhi Impor Gula Indonesia. Berk. Ilm. Pertan. 1, 77-85 (2014).

[3] Tayibnapis, A. Z., Sundari, M. S. \& Wuryaningsih, L. E. Meningkatkan Daya Saing Pabrik Gula Di Indonesia Era Masyarakat Ekonomi Asean. J. Ris. Ekon. dan Manaj. 16, 225 (2016).

[4] Saputro, R. N. \& Purnama, J. ANALISIS PERENCANAAN KEBUTUHAN BAHAN BAKU GULA DENGAN METODE MATERIAL REQUIREMENT PLANNING DI PT. PG CANDI BARU. 105, 129-133 (1945).

[5] Pujitiasih, H., Arifin, B. \& Situmorang, S. Analisis Posisi dan Tingkat Ketergantungan Impor Gula Kristal Putih dan Gula Kristal Rafinasi Indonesia di Pasar Internasional. J. Ilmu-Ilmu Agribisnis 2, 32-37 (2014).

[6] BAIKOW, V. E. Filtration of Mud from Clarifiers. Manuf. Refin. Raw Cane Sugar 111-121 (2013) doi:10.1016/b978-1-4832-3212-6.50016-5.

[7] Cycles, S. Evaporation. Cycle 1897, 44-45 (1989). 
[8] BAIKOW, V. E. Crystallization by Cooling and Motion of Low Grade Massecuites, and the Exhaustion of Final Molasses. Manuf. Refin. Raw Cane Sugar 167-186 (2013) doi:10.1016/b978-1-4832-3212-6.50019-0.

[9] BAIKOW, V. E. Raw Sugar. Manuf. Refin. Raw Cane Sugar 240-254 (2013) doi:10.1016/b978-1-4832-3212-6.50025-6.

[10] Rice, E. F. Storing and Shipping Bulk Sugar. Manufacture and Refining of Raw Cane Sugar (Elsevier B.V., 2013). doi:10.1016/b978-1-4832-3212-6.50021-9.

[11] Silla, H. Separator Design. (2003). doi:10.1201/9780203912454.ch6.

[12] Peters, M. S., Timmerhaus, K. D. \& West, R. E. Plant Design and Economics for Chemical Engineers. (1390). 